\title{
Genotype by environment analysis of rice (Oryza sativa L.) populations under drought stressed and well-watered environments
}

\author{
Lourine Chebet $\mathrm{Bii}^{1,2}$, Kahiu Ngugi $^{1}$, John M. Kimani ${ }^{2}$, George N. Chemining' wa ${ }^{1}$ \\ ${ }^{1}$ Department of Plant Science and Crop Protection, University of Nairobi, Nairobi, Kenya \\ ${ }^{2}$ Kenya Agricultural and Livestock Research Organization (KALRO), Industrial Crops Research Centre, Mwea, \\ Kerugoya, Kenya
}

*Correspondence: chebetm90@gmail.com; kahiu@uonbi.ac.ke

\begin{abstract}
In Kenya, the key abiotic stress affecting rice production is drought stress which is experienced mainly during reproductive phase of the crop. This study evaluated the performance of Kenyan rice populations including 19 generation of crosses, 6 parental and 5 checks under well-watered and drought stressed environment with the aim of identifying the phenotypic traits that confer drought tolerance in rice. The 19 generation of crosses were in $\mathrm{F}_{3}$ when they were evaluated in the short rains season and later advanced to $\mathrm{F}_{4}$ in the long rains season. Nineteen generation of crosses rice (Oryza sativa L.) lines, six parental and five check lines were evaluated for response to drought under drought stressed and well-watered environment. The study was conducted over two seasons in the year 2016/2017 at Kenya Agricultural Livestock Research Organization (KALRO) -Mwea Centre. The experiment was set up in an alpha lattice design with three replications. Drought stress was imposed at panicle initiation by withholding irrigation till physiological maturity meanwhile the well-watered environment continued to enjoy the recommended irrigation regime from planting to physiological maturity. Yield data were scored for drought tolerance. AMMI analysis of variance for grain yield showed that genotypes from crosses of crosses of SARO5XNERICA11, NERICA2XSARO5 and NERICA15XSARO5 expressed high grain yield. AMMI stability Variance (ASV) showed genotypes NERICA15, Duorado Precoce and progenies from crosses of NERICA11XNERICA2, SARO5XKomboka and NERICA2XNERICA11 expressed high stability in both well-watered and drought-stressed environment.

GGE analysis showed that Principal Components (PC1) and PC2 accounted for $96.46 \%$ and $3.54 \%$, respectively. GGE biplots showed that genotypes from crosses SARO5XNERICA11 and NERICA15XSARO5 were the most stable and high yielding. GGE biplots ranked the rice lines as follows: those above average in performance, the stable ones, unstable and those below average in performance. SARO5XNERICA11 is worth of selection due to its high mean yield value and is stable across the mega-environments.
\end{abstract}

Keywords: Environment, Irrigation, Rain-out shelter, Rice grain yield.

Introduction

Rice cultivation in any ecology has many constraints which are either biotic and/ or abiotic. The key abiotic stress affecting optimum rice production is drought (Mostajeran and Rahimi-Eichi, 2009). Kenya is prone to drought stress, with $20 \%$ of country receiving optimal and regular annual rainfall. At the same time, the remaining $80 \%$ receives between $200-500 \mathrm{~mm}$ annual rainfall therefore classified as arid and semi-arid lands (ASALs) (Uhe et al., 2016). Drought can be described as a weather-related incidence of prolonged periods of lack of rainfall which ultimately results in reduced soil moisture content. Drought stress leads to reduced water potential in plant tissues (Haider et al., 2014). Rice plant experience the same due to high transpiration rates as well as lack of water supply to the roots. This results in impaired growth development of the crop subsequently compromising its productivity (Haider et al., 2014). There are several interventions that have been introduced so as to enhance crop yields in drought prone areas. These include reducing evaporation by mulching, better management of water resources, use of advanced irrigation technologies as well as irrigation regimes, breeding cultivars with high water use efficiency and drought tolerance.

Genetic factors of a crop determine its performance in different environments. Modification of the genetic factors by environmental factors such as rainfall and temperature results in genotype by environment $(G \times E)$ interaction. This $G \times E$ interaction indicates phenotypic expression of a trait by a crop. GXE is made up of phenotypic, genetic and environmental variances. GXE interaction have been utilized in many breeding programs in direct selection of a suitable genotype for a specific environment (Sabaghnia et al., 2008). Stability analysis is crucial when profiling performance of crops in various environments. Grain yield stability in addition to biophysical environmental factors, is also affected by management practices and their interaction with environment. For a breeder, to identify promising genotypes in terms of grain yield stability and adaptability, a GXE interaction assessment is always necessary (Ersullo, 2016). Additive Main Effects and Multiplicative Interaction (AMMI) that combines Analysis of Variance (ANOVA) and Principal 
Component Analysis (PCAs) in the analysis of GXE, has proven to be a powerful tool in the identification of patterns of interaction (Krualee et al., 2012). In AMMI ANOVA, genotype and environment are the main effects and PCAs are the multiplicative effect (Krualee et al., 2012). Biplots shows both main and interaction effects and they aid to visualize relationships among genotypes and between environments.

Purchase et al., (2000) developed AMMI Stability Variance (ASV) based on AMMI models, namely, Interaction Principal Component Axes 1 (IPCA1) and Interaction Principal Component Axes 2 (IPCA2) scores for each genotype (Amiri et al., 2013). In this work, the ASV was calculated as shown below:

$$
\mathrm{ASV}=\sqrt{\left.\left[\frac{\text { SS IPCA } 1}{\text { SS IPCA } 2} \text { (IPCA } 1 \text { Score }\right)\right]^{2}+(\text { IPCA } 2 \text { Score })^{2}}
$$

Where $\mathrm{SS}_{\mathrm{IPCA} 1} / \mathrm{SS}_{\mathrm{IPCA} 2}$ is the weight given to IPCA1 by dividing the sum of squares of IPCA1 on the sum of square of IPCA2. According to Purchase et al., 2000, the larger the IPCA scores either positively or negatively, the more specifically adapted a genotype is to certain environments whereas a smaller IPCA score indicates a more stable genotype across environments (Amiri et al., 2013).

In the work reported here, AMMI and ASV models were utilized to evaluate the performance and yield stability of rice genotypes and experimental progenies in advanced generations under drought stressed and well-watered environments.

\section{Results}

Tables 2 and 3 are at the end of the manuscript. The analysis of variance of AMMI model for the 19 generation of crosses, 6 parental and 5 checks over two seasons under two environments show that genotypes accounted for $18.2 \%$ of the total treatment sum of squares, environment explained 64.12\% and Genotype $x$ Environment (GXE) interaction accounted for $12.73 \%$ at $p<0.05$ (Table 2 ).

Table 3 shows how the mean yield of the genotypes varied between environments and seasons. The mean yield of the drought stressed environment varied between 1.0 tha $^{-1}$ and 2.8 tha $^{-1}$ in season 1 and between 0.4 tha- 1 and 3.0 tha- 1 in season 2 (Table 3 ). The average grain yield ranged from in the four environments ranged from 1.9 tha $^{-1}$ to 5.4 tha $^{-1}$ (Table 3). The IPCA for yield of the evaluated lines were also presented in table 3 . Lowest score of IPCA 1 was -0.8 while the highest score was 0.9. IPCA2 ranged from -0.3 to 0.5 (Table 3). The lowest ASV value obtained in this study was 0.2 while the highest ASV value was 16.2 (Table 3).

According to ASV (Table 3), the genotypes with the least score is the most stable. From this study, the ASV ranked genotypes, NERICA 15 <Dorado Precoce <NERICA $11 \mathrm{x}$ NERICA $2<$, SARO 5 x Komboka < NERICA 2 x NERICA 11 as the most stable and NERICA $2 \times$ SARO5 $<$ NERICA $2 \times$ NERICA $1<$ NERICA 1 x NERICA $11<$ Komboka x NERICA 15 <NERICA $15 \times$ NERICA 2 as the most unstable (Table 3 ).

\section{GGE Biplot analysis}

Figures 1-5 and Table 4 are in the attached MS-word.

\section{Discussion}

From these results, it is likely that the difference in yield among the 19 generation of crosses, 6 parental and 5 checks was due to the presence of Genotype $x$ Environment Interaction (GEI). This implies that, selection process may be complicated since GEI decreased the importance of genotypes by affecting their yield performance by reducing the association between phenotypic and genotypic value (Amiri et al., 2013). The large percentage sum of squares indicates significant differences in the averages between the environments leading to variations in yield (Table 2). These genotypes show the possibility of possessing traits that may have positive impact on yield. Parentals NERICA 2(1.9tha $\left.{ }^{-1}\right)$, generation of crosses Komboka x NERICA15 (2.2tha $\left.{ }^{-1}\right)$ and NERICA $2 \times$ NERICA $1\left(.8\right.$ tha $\left.^{-1}\right)$ had the lowest grain yield. These genotypes could possess traits that have negative impact on yield.

These results depict that IPCA1 was sufficient for evaluation of variation in grain yield as explained by GEI (Table 2). Similar results by Oliveria et al., (2013) have been seen in yellow passion fruit where a big percentage of SS is attributed to $E$ and GXE interaction (95\%). ASV is based on IPCA1 and IPCA 2 and has been used to rank stability of wheat and yellow passion fruit. The results from this study showed that there was variability in genotypes in that the 19 generation of crosses, 6 parental and 5 checks responded differently to water stress. This also indicate that there is possible genetic makeup that control yield and yield stability.

Correlation coefficient was approximated by cosine of the angle between two vectors. Acute angles represented positive correlations, obtuse and right angles represented negative correlations and no correlations respectively. Figure 1 shows the angle between well-watered and drought stressed environment is an acute angle showing positive correlations between the two environments.

The Which-Won-Where view of GGE biplot aided in visualizing mega-environments. This biplot was in form of an irregular polygon and a set of lines in red drawn from the point of the biplot origin. The set of lines intersected the sides at a right angle. The vertices of the polygon were genotypes located furthest away from the biplot origin in various directions. The winning genotype for a sector is at the vertex of the sector at the intersection of the two polygon sides whose perpendicular lines form the boundary of that sector. From this biplot, the two environments fell into two sectors with different winning lines. Ray 1 is perpendicular to the sides that connected number 2 and 8 . In the well-watered environment, 2 and 8 (NERICA $1 \times$ NERICA 11 and NERICA $2 \times$ SARO5 respectively) were the winning lines while in the drought stressed environment 17 (SARO5 $\times$ NERICA 11) was the winning line (Figure 2).

Ideal genotype must have the highest mean performance and be absolutely stable. Concentric lines are drawn to help visualize the distance between each genotype and the ideal genotype. The closer a genotype is to the ideal genotype the more desirable it is. Figure 3 ranks genotype with reference to ideal genotype. A genotype is desired if it's closer to the ideal genotype (Farshadfar et al., 2012). From Figure 3, generation of crosses, SARO5 $\times$ NERICA 11(17) and NERICA $15 \times$ SARO 5 (13) fell within the innermost concentric circles and therefore ranked as the best in terms of yield and 
stability. NERICA $1 \times$ SARO 5 was ranked as the next desirable generation of cross while NERICA 2x NERICA 1 was ranked as the most unfavorable since it was far from the ideal line.

The discriminative vs. representative biplot helped in evaluating each test-environment. This biplot was used to answer the following questions: 1 ) Is the test environment able to discriminate the genotypes, in that can it provide much information on the variation of the genotypes? 2) Was the test environment representative of the megaenvironment? and 3) Did the test-environment give unique information about the genotypes?. From this study, the wellwatered environment had a longer vector and therefore it discriminated the rice lines the most but it was nonrepresentative. The drought stressed environment had a shorter vector meaning all genotypes performed similarly in the environment and therefore it provided less information on the differences among the lines. This environment was described as non-discriminating and non-representative. The shorter vector also depicted that the environment was not well represented by $\mathrm{PC} 1$ and $\mathrm{PC} 2$.

The mean vs. stability biplot was used to identify an ideal genotype which is characterized by both high mean performance and high stability. This biplot enabled visualization of genotype's mean performance and their stability across the mega environment. The average environment axis is single-arrowed line passing through biplot origin and the average environment is at the center of the small circle which is the average environment.

Stability of grain yield of genotypes were evaluated by AEC (Average Environment Coordination), where principal components were used in all the environments. A line drawn through $A E C$ and biplot origin is called average environment axis (AEA). AEA points in one direction pointing the genotype main effect. The AEC ordinate separates genotypes with below average means from those above average means. Figure 5 shows the performance of the lines were ranked as follows in this biplot $17>8>13>4>12>7>14>2>16>3>9>27>25$ (Table 4 ) to be above average means.

The mean and stability biplot showed that generation of crosses SARO 5X NERICA 11, NERICA 2 XSARO 5 and NERICA $15 \times$ SARO 5 had the highest grain yield (Figure 5). Stability of the genotypes depend on their projection on to the line drawn through AEC.

17 was the most stable genotype as it was located close to the AEC and had almost zero projection onto the AEA. This was one of the highly consistent line across the environments. Lines 2 and 26 were least stable as they had long projections from the AEA (Figure 5).

The GGE biplots were able to rank the19 generation of crosses, 6 parental and 5 checks based on their performance in the two environments. They were ranked as follows: those above average, below average, stable, unstable and ideal genotypes. Those below average and unstable ones were not given much consideration in selection of rice lines that are high yielding and drought tolerant for a future breeding program. The stable and high yielding ones were important for selection and could be incorporated in a future breeding program SARO 5x NERICA 11 was selected for higher yield and stability across the mega-environments.

\section{Materials and Methods}

\section{Experimental site}

A set of 19 generation of crosses in the $F_{3}$ population, 6 parental and 5 check varieties were obtained from Kenya Agricultural and Livestock Organization (KALRO) - Industrial Crops Research Centre (ICRC) Mwea Tebere. KALRO-Mwea is located in Kirinyaga County, Kenya a distance of $21 \mathrm{~km}$ South West of Embu town and about $112 \mathrm{~km}$ North East of Nairobi. KALRO lies on Latitude $00^{\circ} 37^{\prime} \mathrm{S}$ and Longitude $37^{\circ} 20^{\prime} \mathrm{E}$ and is elevated at 1159 metres above sea level (MASL). The average rainfall is approximately $850 \mathrm{~mm}$ ranging from $500 \mathrm{~mm}$ to $1250 \mathrm{~mm}$ which is divided into long rains between March and June averaging $450 \mathrm{~mm}$ and short rains between mid-October and December averaging $350 \mathrm{~mm}$. This rainfall is defined by unequal distribution in terms of space, time and total amounts. The temperature mean is approximately 220 C (ranging: $15.6^{\circ}$ cto $28.6^{\circ} \mathrm{C}$ ). The soil characteristics are: well-drained dusky-red to dark reddishbrown, nitosol and friable clay. This soil also has low fertility (Jaetzold and Schmidt, 1983).

\section{Germplasm}

The generation of crosses in $F_{3}$ population, 6 parental and 5 check varieties were sown in the short rain season in 2016 . The harvested crop which formed $F_{4}$ population, 6 parental and 5 check varieties were then sown in the long rain season 2017 rainy season. These 19 generation of crosses, 6 parental and 5 check varieties are shown in supplementary Table1 at the end of the manuscript.

\section{Evaluation of $F_{3}$ and $F_{4}$ under well-watered and drought} stressed environments

$19 \mathrm{~F}_{3}$ genotypes, 6 parental and 5 checks were evaluated for response to drought at KALRO-Mwea Centre field station between October 2016 and February 2017 in the first season (short rain season). The two environments: drought stressed and well-watered each sized $12.5 \times 28 \mathrm{M}$ were constructed by erecting poles and covering with a polythene paper to create a rain-free area. In both plots, the field was ploughed, harrowed and raked to obtain a good seedbed for sowing and three seeds per hill were planted on dry land in an alpha-lattice design with a plant to plant spacing of $15 \mathrm{~cm}$ and row to row spacing of $20 \mathrm{~cm}$.

The populations $19 \mathrm{~F}_{3}$ genotypes, 6 parental and 5 checks were randomized in an Alpha Lattice design with three replications in both environments. Standard cultural agronomic practices and plant protection were practiced as per Mwea recommendation. Recommended Nutrient management was achieved by applying $125 \mathrm{kgs} / \mathrm{ha}$ of DiAmmonium Phosphate (DAP, 18:46: 0) fertilizer to each plot at planting. Subsequently, $125 \mathrm{kgs} /$ ha of Calcium Ammonium Nitrate (CAN, 26\%N) fertilizer was applied at vegetative phase as a top-dress. Guard rows of 3 rows were used to surround the plots in order to protect the experimental lines. Irrigation was applied for six hours using overhead sprinkler with the pump at medium speed. In both environments, irrigation was applied for six hours. The wellwatered environment, was irrigated from planting to physiological maturity. However, the drought stressed 
environment, the plants were irrigated from sowing to panicle initiation stage thereafter irrigation was withdrawn for the rest of the crop cycle.

The seeds harvested in season one were in $\mathrm{F}_{4}$ generation of crosses. $19 \mathrm{~F}_{4}$ genotypes, 6 parental and 5 checks were evaluated in the second season (long rain season) in between June 2017 and October 2017. The activities in season 2 were similar to those in season 1.

\section{Data scoring and analysis}

At harvest, yield $/ \mathrm{m}^{2}$ was scored by harvesting, threshing and weighing after winnowing the harvest. The weight was obtained in grams and then converted to the total grain yield in tons per hectare. GENSTAT version 15 was used to carry out AMMI analysis. AMMI combines ANOVA which represent main effects and PCAs (Principal Component Analysis) which represent multiplicative effects. AMMI were obtained under meta-Analysis in GENSTATv15. From the AMMI analysis, IPCA1 and IPCA2 were obtained. In order to measure stability, the following equation that was proposed by Purchase, (1997) was used:

$\mathrm{ASV}=\sqrt{\left.\left[\frac{\text { SS IPCA } 1}{\text { SS IPCA } 2} \text { (IPCA } 1 \text { Score }\right)\right]^{2}+(\text { IPCA } 2 \text { Score })^{2}}$

Where ASV and IPCA are AMMI Stability Variance and Interaction Principal Component Analysis respectively.

AMMI Stability Variance (ASV) was calculated as the distance from the co-ordinate point to origin in two dimensional scatter-gram of IPCA1 scores against IPCA2 scores. IPCA 1 contributed largely to the GEI sum of squares and therefore it has to be weighted. Calculating weighted value enabled compensation of relative contribution of IPCA1 to IPCA2 to the interaction sum of squares (Funga et al., 2017). The weighting was done by obtaining the proportional difference between IPCA1 and IPCA2. Genotypes with the least IPCA1 and ASV were the most stable. Genotype by Environment Analysis for R-Windows (GEA-R) was used to analyze effect of genotype and genotype by Environment (GGE) interaction under well-watered and drought stressed environments through two seasons to obtain GGE biplot. GGE biplots were constructed using two principal components (principal component 1 and principal component 2). GGE biplots graphically displayed patterns of genotypes across environments in a multi-locational trial.

\section{Conclusion}

AMMI analysis showed that SARO5 $\times$ Ner11 recorded a high grand mean yield and also a high ASV value of 9.649. This means that it is an unstable genotype despite the high mean yield. Nerica $2 \times$ Nerica1 had very high ASV value of 12.450 and low yields therefore an unfavourable genotype. Stable genotypes included Nerica 15 and Duorado precoce which recorded low ASV values and medium yield of 3.4 tha $^{-1}$ and 3.1 tha $^{-1}$ respectively and therefore would be suitable parental lines in a breeding program.

GGE biplot showed that there were positive correlations between well-watered and drought stressed environment. The mean and stability biplot show that genotypes from generation of crosses of SARO 5x NERICA 11, NERICA $2 x$ SARO 5 and NERICA $15 \times$ SARO 5 had the highest grain yield. Segregating genotypes from generation of crosses of SARO5 $x$ NERICA 11 and NERICA $15 \times$ SARO 5 ranked as the best in terms of yield and stability. Segregating lines, from populations of NERICA $2 \times$ SARO 5 and NERICA 1 X NERICA 11 were higher yielding in the well-watered environment whereas, genotypes from SARO5 $\times$ NERICA 11 population were the best performing in the drought stressed environment.

\section{Acknowledgements}

The University of Nairobi and Kenya Agricultural Livestock and Research Organization (KALRO)-Mwea Kenya.

\section{References}

Amiri E, Farshadfar E and Jowkar MM (2013) AMMI analysis of wheat substitution lines for detecting genes controlling adaptability. IJABBR. Volume 1 (9):1112-1123.

Ersullo J (2016) Genotype x Environment interaction for grain yield of some field pea genotypes in central and north eastern zones of South Region, Ethiopia. GJPBCS.ISSN:2354-2292.

Farshadfar E, Mahmodi N and Yaghotipoor A (2011) AMMI stability value and simultaneous estimation of yield and yield stability in bread wheat (Triticumaestivum L.) AJCS. 5(13) 1837-1844. ISSN: 1835-2707.

Haider Z, Mehboob A, Razaq A, Khalid UB, Rasool N and Mehmood K (May, 2014).Effect of drought stress on some grain quality traits in rice (Oryza sativa L.) AJAR. 23157720: 2(5)128-133.

Jaetzold $R$ and Schmidt $H$ (1983) Farm management handbook of Kenya. Volume $11 \mathrm{c}$, national conditions and farm management information. East Kenya (Central and Eastern).

Krualee S, Sdoodee S, Eksomtramage T and Sereeprasert V (2012). Stability of fresh fruit bunch of oil palm cross (Elaeis Guineensis Jacq.) in southern Thailand. SABRAO J BREED GENET. 44:1-8.

Mostajeran A and Rahimi-Eichi V (2009). Effects of drought stress on growth and yield of rice (Oryza sativa) cultivars and accumulation of proline and soluble sugars in sheath and blades of their different ages leaves. AEJAES. 5(2):264272.

Oliveria EJD, Freitas JPXD, Jesus OND (2013) AMMI analysis of the adaptability and yield stability of yellow passion fruits. Sci.Agric. v.71: 139-145.

Sabaghnia N, Sabaghpour S H and Dehghani H (2008). The use of an AMMI model and its parameters to analyze yield stability in multi-environment trials. J.Agric.Sci. 146:571 581.

Uhe $P$, Sjoukje $P$, Bilt $D$, Kew $S$, Shah, Kimutai J, Otto $F$, Oldenborgh GJV, Singh R, Arrighi J and Cullen H (2017) The drought in Kenya, 2016-2017.Climate and Development Knowledge Network and World Weather Attribution Initiative. Raising Risk Awareness. Int. J. Climatol. 